Calatayud Díaz, Francisco. Factores de vulnerabilidad del sector pesquero de la provincia de Alicante en el panorama actual. GeoGraphos. [En línea]. Alicante: Grupo Interdisciplinario de Estudios Críticos y de América Latina (GIECRYAL) de la Universidad de Alicante, 6 de junio de 2014, vol. 5, nº 68, p. 313-339 [ISSN: 2173-1276]. [DOI: 10.14198/GEOGRA2014.5.68].

\title{
Ge Graphos
}

REVISTA DIGITAL PARA ESTUDIANTES DE GEOGRAFÍA Y CIENCIAS SOCIALES

$<$ http://web.ua.es/revista-geographos-giecryal>

\section{FACTORES DE VULNERABILIDAD DEL SECTOR PESQUERO DE LA PROVINCIA DE ALICANTE EN EL PANORAMA ACTUAL}

\author{
Francisco Calatayud Díaz \\ Grado de Geografía y Ordenación del Territorio \\ Universidad de Alicante (Alicante, España) \\ Correo electrónico: fcd2@alu.ua.es
}

Recibido: 3 de junio de 2013. Devuelto para revisión: 14 de julio de 2013.

Aceptado: 6 de junio de 2014

\section{RESUMEN}

El sector de la pesca en la provincia de Alicante se encuentra en una situación de retroceso que pone en peligro una actividad económica con una larga tradición en nuestra sociedad. Una situación que no siempre ha sido así pues antes de la adhesión de España a la Unión Europea, la flota alicantina era considerada una potencia pesquera en el Mediterráneo. A partir de este momento, junto con la falta de rentabilidad que acusa el sector en las últimas décadas han sido factores determinantes para que cada año disminuya el censo de embarcaciones de las Cofradías de la provincia. Las ayudas de la Política Pesquera Común al cese de la actividad, un sector envejecido y sin mano de obra joven y cualificada son el resto de ingredientes que llevan a la pesca a una crisis que será difícil de revertir.

Palabras clave: Sector pesquero, Política Pesquera Común, cofradías de pescadores, artes de pesca. 


\title{
VULNERABILITY FACTORS OF FISHERY IN ALICANTE PROVINCE AT THE PRESENT TIME
}

\begin{abstract}
The fishery in Alicante Province are in a critical situation. It have an important tradition in our society and now this economic sector is in risk. This situation hasn't always been like at the moment. Before Spain became in member state of the European Union, Alicantina fleet was considered the most important in the Mediterranean Sea. From this point on, along with lack of profitability of the sector during the last decades, both had been decisive so that the number of ships in Fisherman's Association had been gone down each year. The aid of the Common Fishery Policy to the stop of the activity, aged sector and without young and qualified workforce are the other ingredients that lead to a crisis that fishery will be difficult to reverse.
\end{abstract}

Key words: Fishery, Common Fishery Policy, Fisherman's Association, Fishering Techniques.

\section{VULNERABILIDADES DO SECTOR DAS PESCAS NA PROVINCIO DE ALICANTE NA SITUAÇAO ATUAL}

\section{RESUMO}

O sector das pescas na provincio de Alicante se encontra em uma situação de retrocesso que pnha em perigo uma actividade economica com uma longa tradição na nossa sociedade. Uma situação que nem sempre foi assim, pois antes da união da Espana a União Europeia a frota alicantïna era considerada uma potencio pesquera no Mediterraneo apartir desse momento, junto com a falta de recurso que acusa o sector mas ultimas decadas que an sido factoers determinados para que cada ano disminuice o censo das embarcaçãos das cofradias e provincias, as ajudas da Política Comum das Pescas ao paro da atividad um sector envelhecido e sem mão de obra jovem e cualificada são a resto de engredientes que levam a paseca a uma crise que sera dificil que se repita.

Palavras-chave: Sector de pesca, Política Comum das Pescas, cofradias, artes de pesca.

\section{INTRODUCCIÓN}

El tema del sector pesquero en la provincia de Alicante no es una tarea sencilla de abordar ya que la información es escasa y en su mayoría estadística. Esta circunstancia plantea la necesidad de profundizar en un sector que antaño vivió una época de esplendor y que a día de hoy ve peligrar su subsistencia. En épocas pasadas la pesca alicantina era una potencia en todo el Mediterráneo, situación que se ha revertido en la actualidad estando realmente en un estado muy vulnerable.

Metodológicamente, en un primer momento, se contextualizará el sector pesquero a diferentes niveles para observar cómo la pesca supone un importante nicho económico que necesita la atención pertinente para no perder competitividad. A un nivel más próximo se presenta la pesca valenciana y cómo Alicante es la provincia más destacada en este sector de actividad dentro del conjunto de la Comunidad, entre las que destacan 
Cofradías como la de Santa Pola o Villajoyosa. Posteriormente a partir las cifras proporcionadas por la Federación Provincial de Cofradías de Pescadores se comprobará la evolución de sector pesquero en nuestro territorio. La presentación de los datos de las diferentes cofradías se ha agrupado siguiendo una delimitación geográfica, como son las comarcas costeras de la provincia.

Posteriormente se expondrán los problemas que en el siglo XXI hacen peligrar un sector con una larga tradición en nuestras tierras, ya que la mayoría de ciudades de la costa mediterránea alicantina tienen sus orígenes en poblaciones marineras, donde el arraigo de la gente al mar dio como resultado un modo de vida donde son numerosas las aportaciones de productos pesqueros a nuestra alimentación, cultura y gastronomía.

Actualmente España, según la FAO, se encuentra dentro de los 25 países con un mayor volumen de capturas según los datos del año 2010 (Figura 1). Además, España es uno de los principales países consumidores de pescado y frutos del mar del mundo. El consumo nacional se sitúa en 1.956.233 toneladas mientras que el individual, expresado en kilogramos por persona y año, es de 42,9.

Figura 1. Producción pesquera mundial, por captura, en 2010

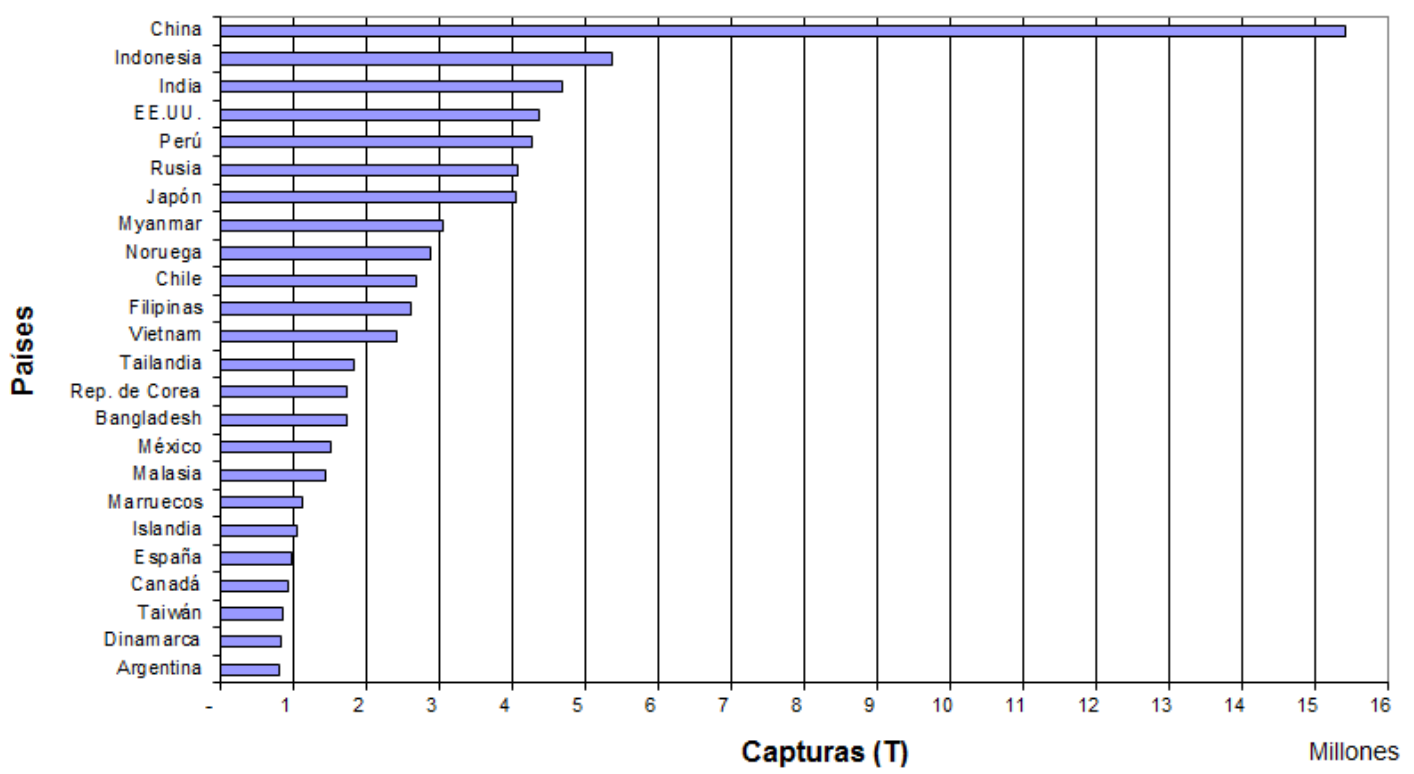

Fuente: FAO. Elaboración propia.

A nivel europeo, España ocupa una posición destacada dentro de la producción pesquera según los datos de EUROSTAT. Desde la oficina estadística de la Comisión Europea se hace una distinción entre el volumen de capturas en cualquier área pesquera del planeta y entre las realizadas en el Mediterráneo. En la evaluación global las capturas españolas se sitúan a la cabeza, tras las de países como Noruega y Dinamarca, mientras que en la circunscripción mediterránea sólo nos supera el volumen de producción de Italia y Turquía.

La flota pesquera española no sólo faena en el Mediterráneo, denominado por la FAO como Major Fishing Area 37 - Mediterranean and the Black Sea, sino que se distribuye 
por otros caladeros de aguas de la Unión Europea y por otros internacionales. En cuanto a las embarcaciones alicantinas su zona de captura se centra principalmente en el Área 37.1.1 - Mediterráneo occidental división de Baleares.

Hay que dejar claro la diferencia entre desembarco en un puerto y capturas realizadas por un buque, ya que estos datos en numerosas ocasiones no son coincidentes.

El desembarco de las capturas de los barcos españoles se lleva a cabo por lo general en los puertos españoles, normalmente en los de su propia Comunidad Autónoma. De este modo los puertos y sus lonjas se convierten en centros de actividad económica que generan dinámicas de trabajo en los municipios de su entorno. Sin embargo estos puertos también reciben mercancía de buques extranjeros, mientras que a los puertos nacionales del Mediterráneo también llegan productos de pesqueros foráneos, como por ejemplo franceses que quieren vender sus capturas en nuestras lonjas.

En cuanto a las artes de pesca que se emplean en España, el $80 \%$ de los buques están vinculados a las artes menores, y por lo tanto se trata de barcos de pequeño tamaño con o sin motor que emplean una gran variedad de instrumental y técnicas.

\section{Cuadro 1. Distribución de embarcaciones y descargas a nivel nacional en 2005}

\begin{tabular}{|l|c|c|}
\hline \multicolumn{1}{|c|}{ Comunidad Autónoma } & Número de embarcaciones & Tasa descargas realizadas (\%) \\
\hline Galicia & 6.840 & 24,38 \\
\hline Andalucía & 2.018 & 11,88 \\
\hline Cataluña & 1.263 & 12,19 \\
\hline Canarias & 1.154 & 17,5 \\
\hline C. Valenciana & 837 & 8,75 \\
\hline Baleares & 475 & 5,31 \\
\hline Asturias & 409 & 7,81 \\
\hline País Vasco & 305 & 7,5 \\
\hline Murcia & 277 & 1,25 \\
\hline Cantabria & 184 & 2,81 \\
\hline Ceuta y Melilla & 68 & 0,62 \\
\hline
\end{tabular}

Fuente: FAO. Elaboración propia.

A pesar del peso que España tiene a nivel internacional, en el PIB la agricultura y la pesca tan sólo representan el 2,7\%, reflejo de la disminución tanto de explotaciones agrarias como de embarcaciones pesqueras consecuencia de políticas europeas que han fomentado el abandono de la actividad en el sector primario.

En la Comunidad Valenciana, el sector de la agricultura, ganadería y pesca en el año 2011 ha continuado su retroceso situándose la primera estimación en el 3.9\%, con lo que lleva una serie de cuatro años continuados experimentando caídas superiores al $3 \%$. Lo que evidencia la profunda crisis en la que se encuentra sumergido el sector.

La persistencia de una situación de crisis como la actual ha provocado un aumento del número de embarcaciones que acaban en los desguaces. Si se compara el número de barcos que había en activo hace tan solo dos años, en el 2009, se advierte como su número ha descendido un $7.10 \%$ siendo la provincia de Alicante con un $4.40 \%$ dónde 
menor número de barcos han desaparecido (Figura 2). En cambio la tendencia varía en cuanto a la producción de capturas y el valor que adquieren en lonja, salvo Castellón que sigue la tónica de descenso, tanto Alicante y especialmente Valencia, han experimentado una mejoría en ambas cuentas de resultados (Figura 3).

Figura 2. Evolución barcos y tripulación, años 2009 y 2011

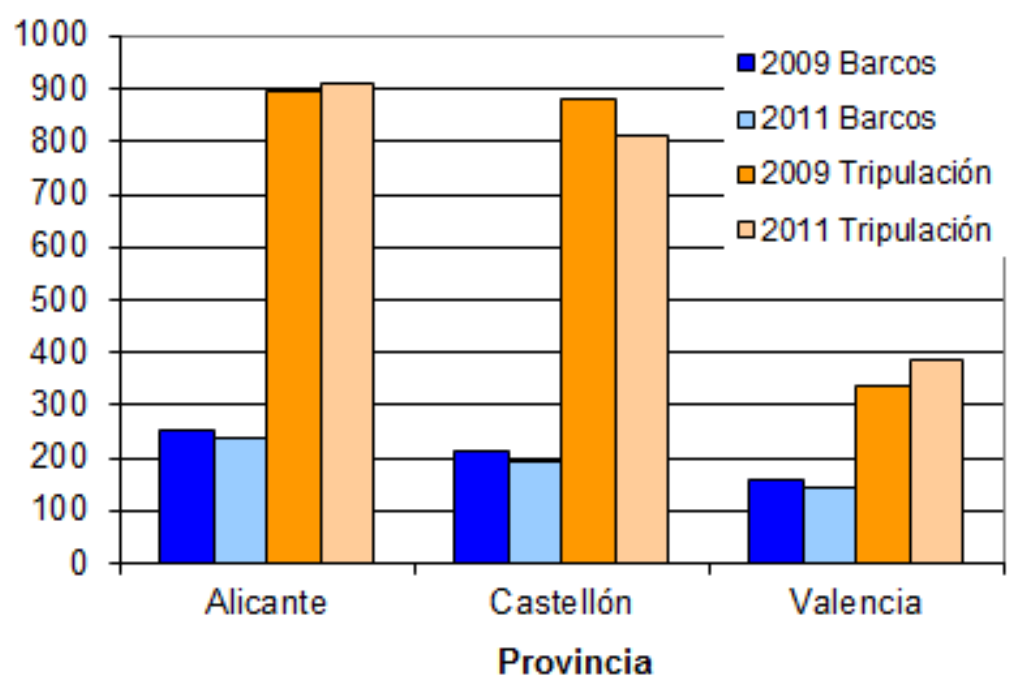

Fuente: Memoria de la situación socioeconómica y laboral de la Comunidad Valenciana 2009 y 2011. Elaboración propia.

Figura 3. Evolución capturas y su valor en lonja, años 2009 y 2011

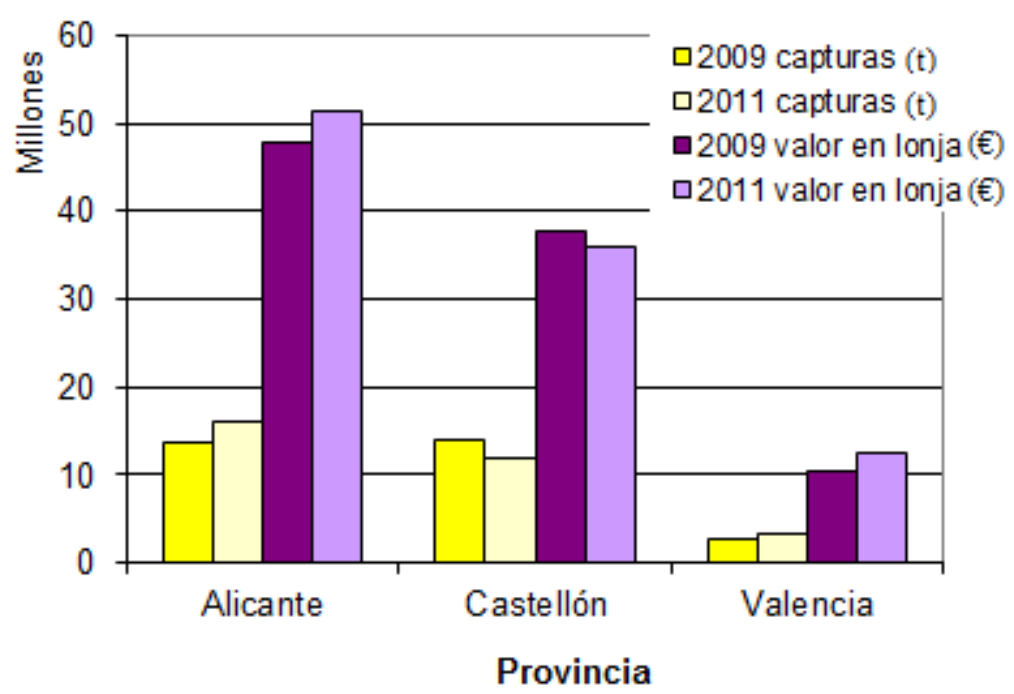

Fuente: Memoria de la situación socioeconómica y laboral de la Comunidad Valenciana 2009 y 2011. Elaboración propia. 


\section{LAS FAENAS DE PESCA DEL SECTOR PESQUERO ALICANTINO}

La pesca se puede definir como el arte de capturar peces para el consumo, entendiendo como arte, los diferentes mecanismos empleados para la captura. La variedad de artes de pesca empleados está íntimamente ligada a la especie de pez, crustáceo o molusco que se desea capturar. Existen cofradías de pescadores en Alicante cuya flota está más especializada en uno u otro método, así se habla de embarcaciones de arrastre, de cerco $\mathrm{u}$ otras artes.

\section{Figura 4. Esquema de una red de arrastre}

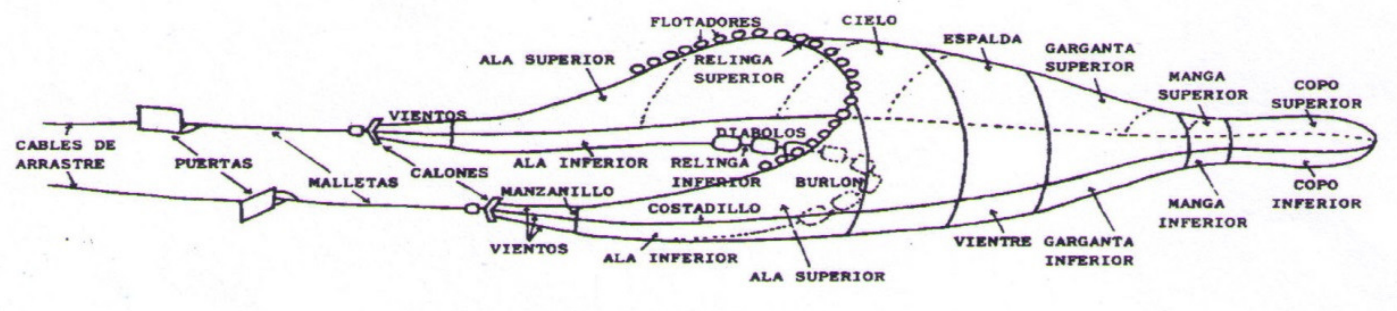

ESQUEMA GENERAL DE UNA RED DE ARRASTRE Y SUS PARTES

Fuente: Federación Provincial de Cofradías de Alicante.

La pesca de arrastre de fondo (Figura 4) consiste en un aparejo de enmalle con forma de bolsa que es remolcada por un barco con la finalidad de capturar las especies que viven en el fondo marino. La pesca de arrastre se practica de lunes a viernes y las embarcaciones salen de puerto a las $5.00 \mathrm{~h}$ y regresan antes de las $18.00 \mathrm{~h}$. Este arte de pesca sólo está permitido en fondos no inferiores a 50 metros frente a nuestras costas y en el canal de Ibiza - Alicante. Las especies que se capturan son principalmente de marisco, aunque también se obtienen moluscos y peces redondos de fondo.

Figura 5. Esquema del arte de cerco

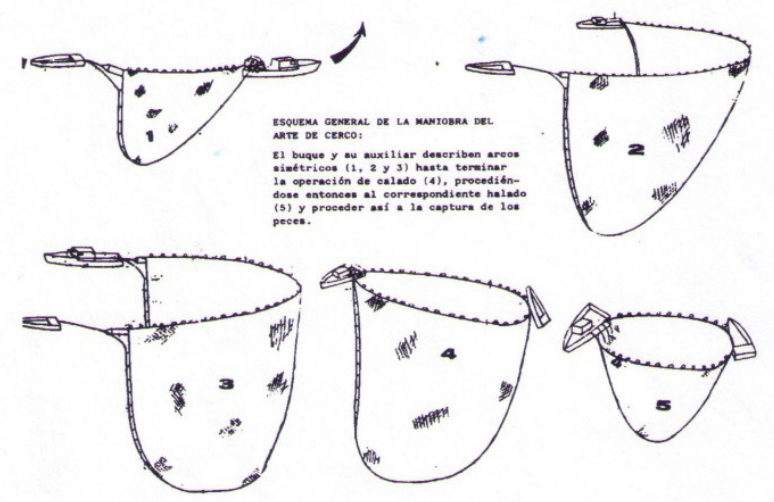

Fuente: Federación Provincial de Cofradías de Alicante.

La pesca de cerco (Figura 5) es una modalidad que busca la captura de los bancos de peces que nadan en aguas próximas a la superficie. La triaña es el arte de cerco más empleado en la provincia de Alicante. Cuando el banco de peces queda atrapado en el 
aparejo, atraídos por la luz intensa que emite el bote de luces o chinchorro, se "copea" o se sube el pescado a bordo. Por sus características es un arte que se practica por la noche, de lunes a viernes, saliendo generalmente al oscurecer y regresando de día. Se lleva a cabo en fondos no inferiores a 35 metros y la gran movilidad de los bancos de peces provoca que los barcos inviertan mucho tiempo en localizarlos. Generalmente se obtiene por este arte pescados que viven entre aguas, como los pescados azules.

\section{Figura 6. Esquema simplificado de un trasmallo}
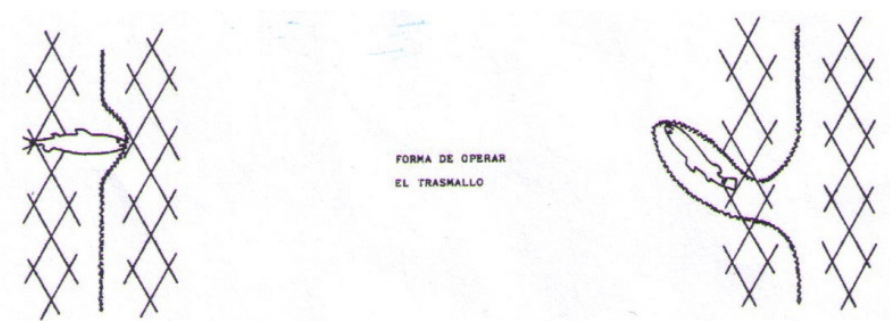

Fuente: Federación Provincial de Cofradías de Alicante.

Las artes menores empleadas en Alicante son numerosas y variadas, de las que destacaremos las más relevantes. El trasmallo (Figura 6) es un arte de pesca de superficie o de fondo, consistente en una triple malla, de mayor calado las exteriores que la interior, donde quedan atrapados todo tipo de peces y crustáceos. Es una de las artes más artesanales que se practican, empleada por embarcaciones de pequeño tamaño que salen a faenar todos los días excepto los sábados, a cualquier hora del día. Las artes de palangre (Figura 7) consisten en un cabo del que prenden una serie de anzuelos. La profundidad de calado y la especie que se pretende capturar determinan sus dimensiones máximas y el número de anzuelos permitidos, que oscilan entre los 2.000 o 10.000 por barco. En la provincia no existen muchos barcos que empleen este arte debido a que se necesita invertir muchas horas. Se capturan principalmente especies migratorias y de hábitat rocoso.

Las nasas es un arte-trampa de forma cilíndrica con un cebo en su interior y una abertura circular que permite entrar al pez o crustáceo, y por la que luego es muy difícil salir. En Santa Pola se emplea fundamentalmente para la captura de quisquilla. El alcatruz o cadufo, es otro arte-trampa más elemental, se trata de una ánfora de barro que una vez calada en los fondos rocosos, el pulpo, encuentra un refugio natural. Muy extendida en el norte de la provincia.

Figura 7. Esquema de un aparejo de palangre de fondo

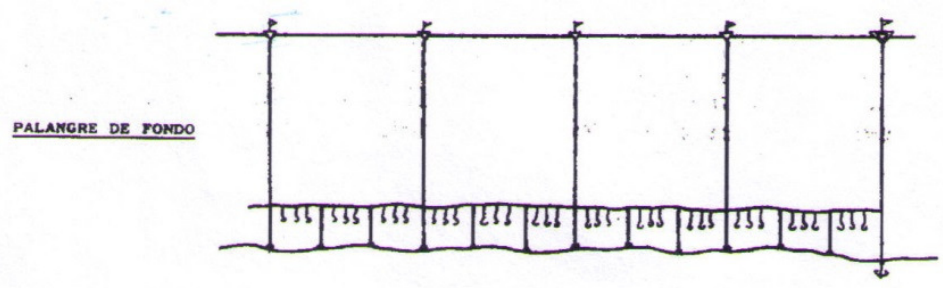

Fuente: Federación Provincial de Cofradías de Alicante. 
Todas las embarcaciones que faenan en nuestras aguas suelen desembarcar sus capturas de forma diaria en la lonja correspondiente para su venta directa a través del sistema de subasta. En el cuadro siguiente se muestran las especies cuyas captura son más representativas, según dos variables, por un lado el volumen de kilos desembarcados y su valor en lonja en euros durante el año 2012.

\section{Cuadro 2. Especies con mayor volumen de captura y valor en lonja}

\begin{tabular}{|l|c|c|c|}
\hline Especie & Valor en lonja $(€)$ & Kg desembarcados & $€ /$ kg (promedio) \\
\hline Gamba & 6.708 .898 & 245.440 & 27,33 \\
\hline Sardina & 3.987 .367 & 2.253 .326 & 1,77 \\
\hline Cigala & 3.386 .016 & 186.283 & 18,18 \\
\hline Boquerón & 3.249 .571 & 1.084 .376 & 3,00 \\
\hline Pulpo & 3.197 .332 & 681.750 & 4,69 \\
\hline Pescadilla & 3.122 .205 & 512.358 & 6,09 \\
\hline Salmonete & 2.142 .496 & 303.623 & 7,06 \\
\hline Rape & 1.702 .406 & 305.984 & 5,56 \\
\hline Calamar & 1.572 .139 & 149.530 & 10,51 \\
\hline Bacaladilla & 1.306 .011 & 496.163 & 2,63 \\
\hline Quisquilla & 803.738 & 42.944 & 18,72 \\
\hline Alacha & 772.817 & 2.034 .943 & 0,38 \\
\hline Jurel & 460.644 & 370.012 & 1,24 \\
\hline Melva & 305.604 & 313.039 & 0,98 \\
\hline Langosta & 143.653 & 5.106 & 28,13 \\
\hline Lenguado & 118.490 & 5.921 & 20,01 \\
\hline Langostino & 96.224 & 2.767 & 34,78 \\
\hline Mero & 59.596 & 3.524 & 16,91 \\
\hline Rodaballo & 25.422 & 1.092 & 23,28 \\
\hline
\end{tabular}

Fuente: Federación Provincial de Cofradías de Pescadores. Elaboración propia.

Todas las artes y sistemas deben cumplir un estricta reglamentación con el fin de no agotar los recursos pesqueros y permitir la actividad en el tiempo. Las características de cada arte se describen perfectamente en una normativa elaborada por los pescadores a través de las cofradías, en las que además se recogen los periodos de pesca, anzuelos reglamentarios junto con las paradas temporales y biológicas. Todo ello para hacer posible la continuidad de la actividad pesquera, siempre y cuando no se altere la calidad de las aguas.

\section{LAS COFRADÍAS DE PESCADORES EN LA PROVINCIA DE ALICANTE}

Las Cofradías de pescadores son Corporaciones de Derecho Público, sin ánimo de lucro, con personalidad jurídica propia, con plena capacidad de obrar que integran voluntariamente y libremente a los profesionales de la pesca, armadores y trabajadores del sector pesquero de bajura y artesanal. Están reguladas por el Real Decreto 670/78.

El objetivo fundamental es el incremento y desarrollo de la actividad pesquera de modo que suponga para el sector un aumento de su rendimiento así como la mejora del bienestar moral y material de todos los trabajadores afiliados a la cofradía. Además 
sirven de enlace con la Administración y como órgano de consulta para la redacción de normas vinculadas con el sector.

En España los antecedentes a las cofradías se sitúan en las organizaciones "soladitates" de época romana en las el elemento religioso se vincula con el profesional. Pero es en la Edad Media cuando surgen con una estructura y unas funciones de las que las cofradías actuales son herederas. Por consejo de los monjes Benedictinos de Cluny, en el siglo XI, los pescadores se agruparon en hermandades, cuyas actividades consistían en la vigilancia y defensa ante los corsarios, dar socorro a las víctimas y familias en caso de siniestro y velar por los intereses de los pescadores, de modo que se organizaban y reglamentaban las actividades pesqueras. El mando de la flota local se asignaba a un patrón veterano llamado el Patrón Mayor ya que su experiencia permitía una mejor ordenación de las salidas y regresos de los buques a faenar.

En la provincia de Alicante se conocen cofradías de época medieval, como las Cofradías de San Jaime y San Andrés. Sus miembros pescadores alicantinos tenían un papel destacado en la rogativa de Santa Faz, junto al Ayuntamiento y los caballeros del vino. En Altea hay documentos que prueban que la Asociación de Pescadores y Mercantes data de 1867, la Sociedad de Socorros Mutuos "Hijos de la Noche" de 1902 y de 1918 la Sociedad de Pescadores "La Marítima".

La estructura de las actuales cofradías cuenta con una Junta General, como órgano supremo de decisión, compuesto en paridad de armadores-empresarios y trabajadores de la mar y representa a todos los pescadores, tripulantes y armadores. La Junta de Cabildo o Directiva es la encargada de llevar a la práctica los acuerdos de la General. Todos los órganos, tanto de gobierno como de gestión, están presididos por el Patrón Mayor, cargo electo cada cuatro años según un proceso electoral.

Desde 1963 existe una asociación superior que aglutina a toda las entidades de la provincia, la Federación Provincial de Cofradías de Pescadores de Alicante, que las coordina y representa en temas de interés común.

Las cofradías además de velar por el bien común del sector pesquero desarrollan los siguientes servicios:

- Venden las capturas mediante subasta en la lonja que explota la propia cofradía, asegurando a las embarcaciones el cobro de la venta.

- Mediante las ventas, colaboran con la Administración en el cobro de impuestos, como el IVA, tarifas portuarias, Seguros Sociales, etc.

- Garantiza el suministro de hielo y otros elementos como sal, envases, combustible o pertrechos instalados a pie de muelle.

Las Cofradías de pescadores, en definitiva, son el eje estructurante sobre el que se basa la actividad marítimo-pesquera y por ello cualquier propuesta por desmantelar una corporación que ha prevalecido en el tiempo, sabiendo adaptarse a las circunstancias de cada época, no puede justificarse con argumentos de que éstas, son obsoletas ni mucho menos desfasadas. Gracias a las cofradías, a su eficiencia y organización, se ha continuado manteniendo una actividad con unas características peculiares que merece el mismo apoyo que la agricultura y la misma consideración por parte de la sociedad. 
En la provincia de Alicante, actualmente están constituidas trece cofradías de pescadores. Este elevado número de cofradías, contrasta con lo que sucede en Valencia y Castellón donde tan sólo existen 5 y 4, respectivamente. A excepción de la de Sagunto en Valencia, las ocho restantes se pueden calificar como cofradías grandes donde la más pequeña es la de Valencia con 24 barcos y da trabajo a 85 tripulantes y la más grande la de Gandía con 60 embarcaciones y 158 trabajadores. Si obtenemos el tamaño medio de una cofradía de Valencia y Castellón, ésta estaría compuesta por 37 barcos y 134 tripulantes, mientras que si incluimos la provincia de Alicante el volumen de embarcaciones y trabajadores baja hasta valores de 26 embarcaciones y 95 tripulantes. De las cofradías de Alicante, comparándolas con estos datos, tan sólo dos de ellas, Villajoyosa y Santa Pola, superan la media valenciano-castellonense, mientras que si se comparan con la media de la comunidad, a las dos anteriores hay que agregar la Cofradía de Dénia.

Figura 8. Proporción de embarcaciones en la provincia de Alicante por Cofradías
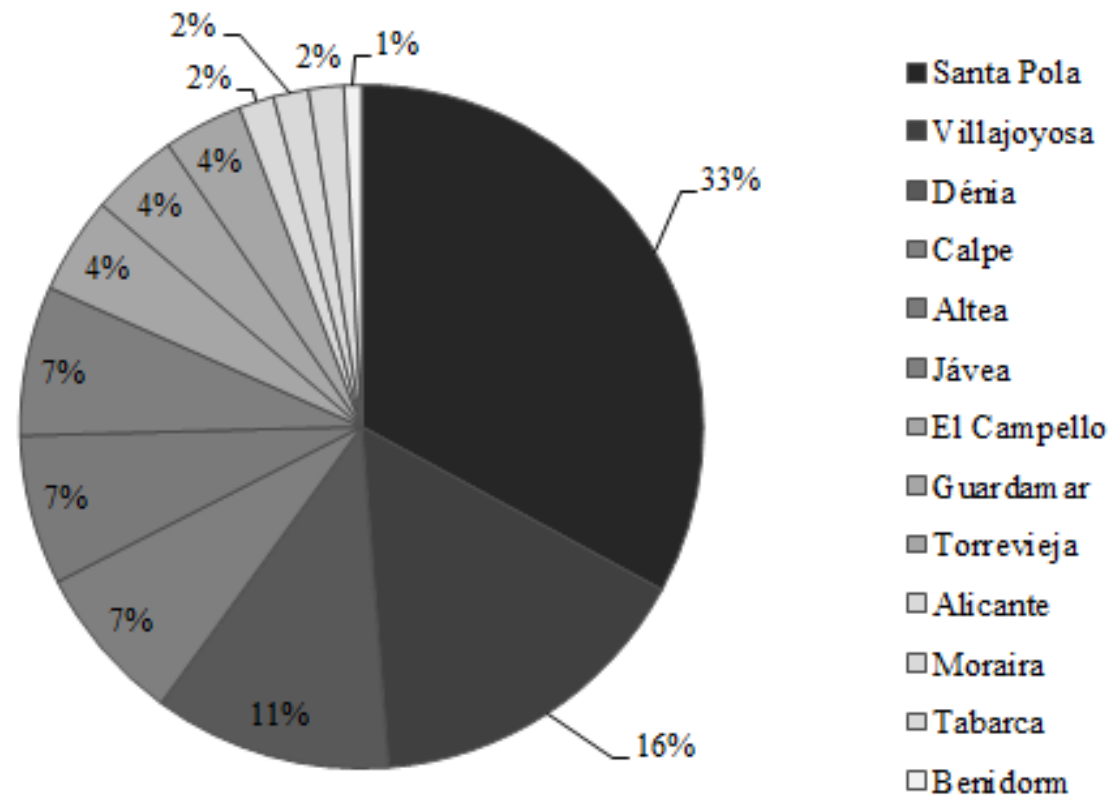

Fuente: Federación Provincial de Cofradías de Pescadores. Elaboración propia.

Estas comparaciones sirven para ver que el territorio pesquero alicantino se encuentra muy fragmentado en pequeñas cofradías (Figura 8). Esta situación es el resultado de la importancia histórica de la provincia en el sector pesquero. Sin embargo en apenas 50 años ha pasado de tener una flota cercana a los 500 barcos a verse reducida en menos de un 50\%, contando en 2011 con 239 embarcaciones. Más acusado es la reducción de la tripulación que para el mismo periodo se han destruido más de 3.000 empleos. De modo que en el panorama actual el tamaño medio de una cofradía alicantina es de 18 barcos y 69 tripulantes, a la luz de estos datos, se refuerza la idea de la dispersión que el sector experimenta en Alicante, frente a la concentración que se da tanto en Valencia como en Castellón.

Sería interesante plantearse si esta atomización de la pesca alicantina resta eficiencia, competitividad y rentabilidad al sector y si una fusión de cofradías y de lonjas daría mayor dinamismo a aquellas que a día de hoy carecen de los medios para competir con 
las lonjas de las cofradías más fuertes, como las de Dénia, Villajoyosa y Santa Pola. De modo que si una embarcación de una pequeña cofradía desembarca sus capturas en una lonja con más cuota de mercado podría ver aumentar sus ventas puesto que la afluencia de compradores es mayor que la que acude normalmente a su lonja de base.

Después de una visión más global se procede a realizar un pequeño análisis de cada una de las cofradías aglutinadas por comarcas, así hablaremos de las Cofradías de la Marina Alta, de la Marina Baixa, de l’Alacantí y del Baix Vinalopó y Baix Segura.

\section{Cofradías de la Marina Alta}

La comarca de la Marina alta es la más septentrional de todas las comarcas de la provincia de Alicante. En el ámbito territorial de esta zona se ubican las Cofradías de Dénia, Jávea, Moraira y Calpe, distribuidas de norte a sur por el litoral.

\section{Figura 9. Evolución de la flota según Cofradía}

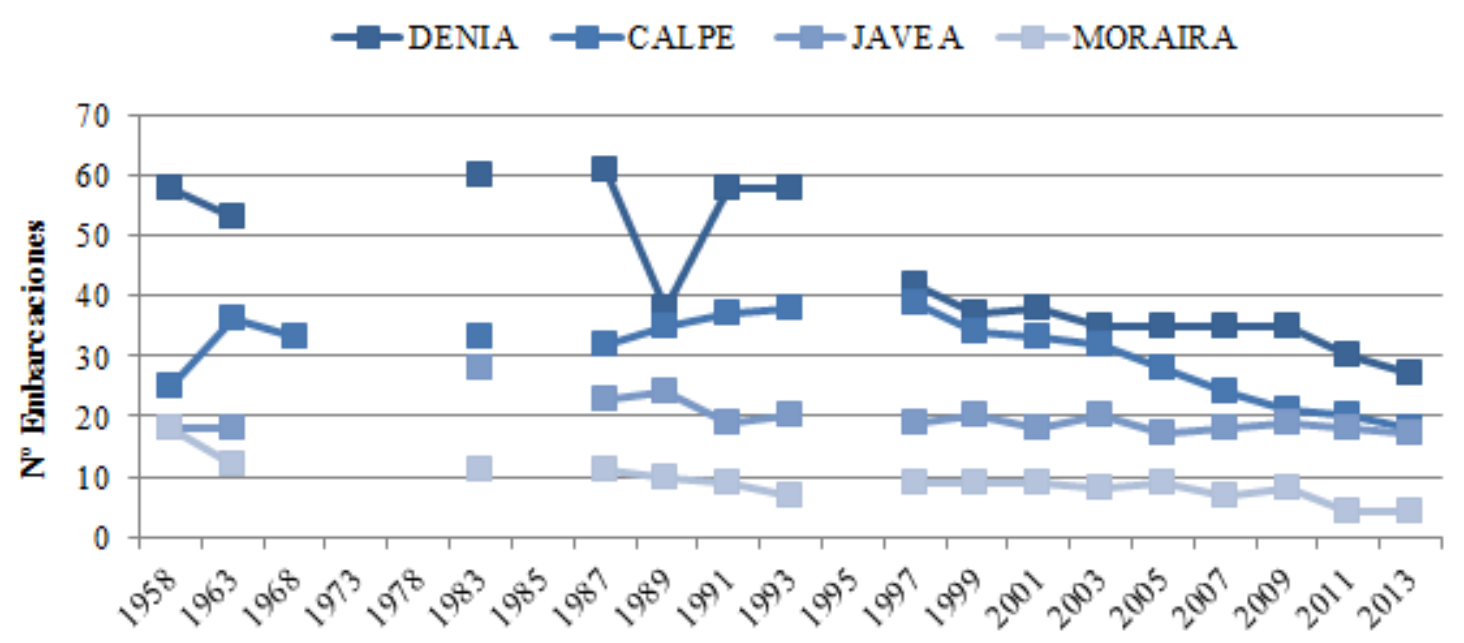

Fuente: Federación Provincial de Cofradías de Pescadores. Elaboración propia.

Figura 10. Proporción de barcos por cofradías en la Marina alta

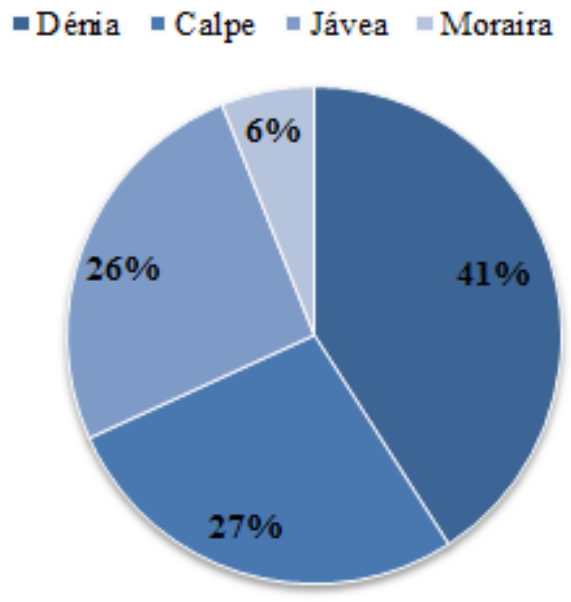

Fuente: Federación Provincial de Cofradías de Pescadores. Elaboración propia. 
Estas cofradías aglutinan un total de 66 barcos de los cuales 34 de ellos se dedican principalmente al arte del arrastre y 27 barcos a las artes menores. De las cuarto, la Cofradía de Dénia aglutina el $41 \%$ de la flota. En cuanto a empleo, la de Dénia sigue estando a la cabeza con 94 tripulantes seguida de Jávea con 90. La Cofradía de Moraira únicamente dispone de buques que faenan otras artes. Calpe no dispone de barcos de cerco mientras que Jávea posee la mayor flota de este arte con 4 embarcaciones.

Las lonjas de los puertos de Dénia, Jávea y Calpe cuentan con unas modernas instalaciones en las que han perfeccionado el sistema de subasta. Además se ha mejorado el proceso de manera que el pescado sufre las mínimas manipulaciones y el tiempo estimado en lonja es más o menos de media hora. La lonja de Moraira, sin embargo, ha optado por la venta directa al público por lotes de hasta tres kilogramos.

\section{Cofradías de la Marina Baixa}

En la demarcación de la Marina Baixa se localizan las Cofradías de Altea, Benidorm y Villajoyosa. Cuentan con un total de 57 barcos, distribuidos según las siguientes artes, 39 de arrastre, 3 de cerco, y 15 de otras artes.

En este bloque se encuentra la Cofradía de Villajoyosa, segunda en importancia de la provincia aunque muy lejos de la Cofradía de Santa Pola. La Vila abastece a toda la zona del interior de la provincia, abarcando una importante área de influencia. De las 38 embarcaciones con las que cuenta esta cofradía, 29 son de arrastre y el resto de otras artes, a excepción de la pesca de cerco que únicamente se realiza en la Cofradía de Altea para la captura del boquerón. Los diferentes procesos de reconversión de la flota han mermado considerablemente en número de embarcaciones de Villajoyosa, de hecho en los años 50 y 60, los buques de esta cofradía salían a faenar a aguas del Atlántico. La Cofradía de Benidorm compuesta, en 2013, tan sólo por dos embarcaciones de artes de pesca en aguas cercanas al litoral ha visto como su actividad pesquera ha sido desplazada por el turismo que resulta más rentable y donde los marineros han cambiado la pesca por el cuidado de embarcaciones de recreo.

\section{Figura 11. Evolución de la flota según Cofradía}

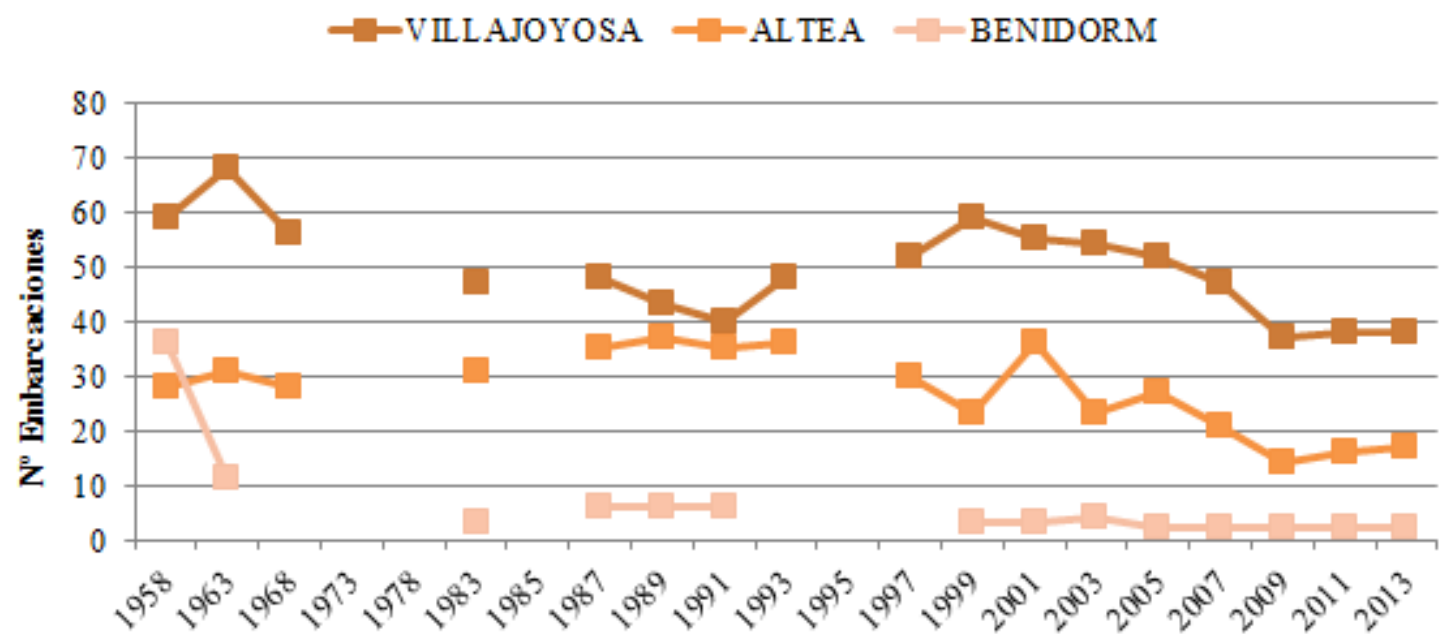

Fuente: Federación Provincial de Cofradías de Pescadores. Elaboración propia. 


\section{Figura 12. Proporción de barcos por cofradías en la Marina baixa}

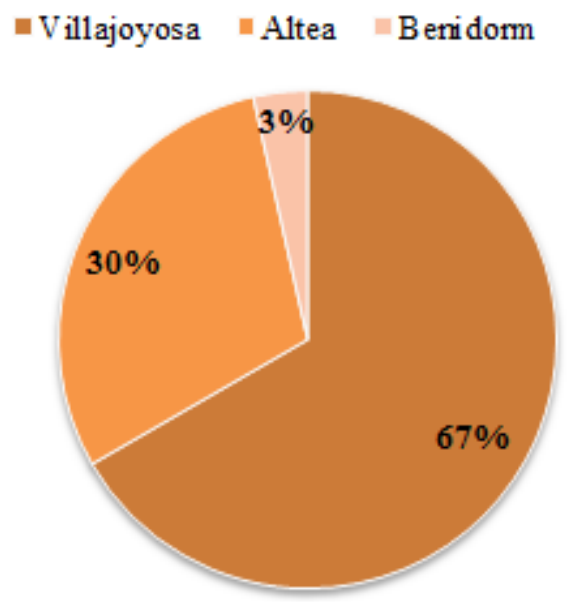

Fuente: Federación Provincial de Cofradías de Pescadores. Elaboración propia.

En cuanto al desembarco de las capturas, Villajoyosa y Altea, la realizan en sus propias lonjas mientras que la de Benidorm vende sus capturas en la lonja de Villajoyosa, principalmente. Las dos lonjas de la comarca han experimentado el mismo proceso de modernización que las anteriores.

\section{Cofradías de l'Alacantí}

La comarca de l'Alacantí cuenta tan sólo con dos cofradías muy pequeñas, la Cofradía de El Campello con 11 embarcaciones y la Cofradía de Alicante con 4 barcos. En ambas la faena principal son las artes no vinculadas al arrastre ni al cerco.

La pérdida de embarcaciones en Campello se inicia a principios de los noventa del pasado siglo. En el año 1983 contaba con un total de 36 embarcaciones, de las cuales 15 eran de arrastre, en 1994 se reduce la flota a 22, de ellas ya tan solo 10 son de arrastre, número que en 1996 ya queda reducido a la mitad, contando con 17 embarcaciones en total. La tendencia ha continuado y los barcos registrados en 2013, sólo dos, son de arrastre. La lonja de El Campello, al igual que la de Moraira, vende directamente al público en lotes pequeños de unos tres kilos.

El caso de la Cofradía de Alicante, lo analizaremos en un apartado aparte ya que su situación no está relacionada con las ayudas al desarme del sector de la Política Pesquera Común ni con el envejecimiento de un sector que carece de un reemplazo generacional, motivos que están detrás del retroceso que sufren el resto de cofradías. La lonja de Alicante en la actualidad se encuentra clausurada y embargada 
Figura 13. Evolución de la flota según la Cofradía

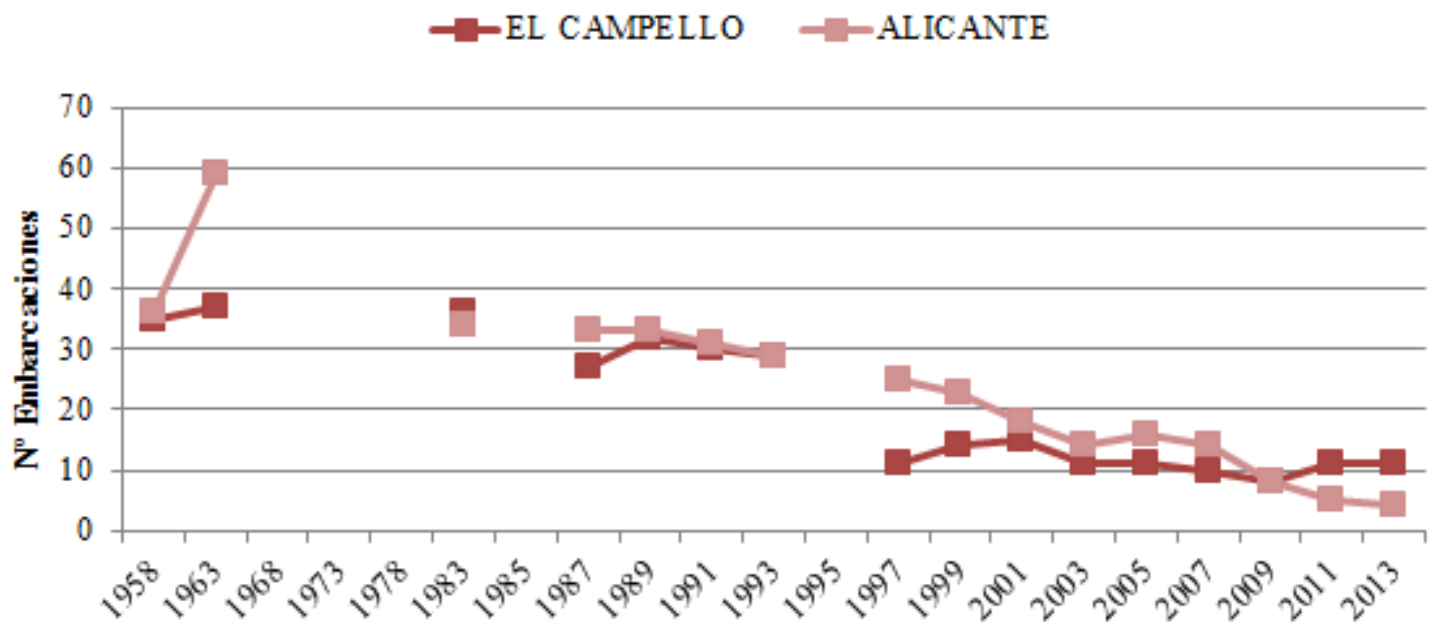

Fuente: Federación Provincial de Cofradías de Pescadores. Elaboración propia.

\section{Cofradías del Baix Vinalopó y del Baix Segura}

El ámbito que se abarca en el siguiente epígrafe es el territorio de las comarcas más meridionales de la provincia, el Baix Vinalopó y el Baix Segura o Vega Baja. Se tratan unidas las cuatro cofradías que tiene sus puertos base en el sur de la provincia porque las Cofradías de Tabarca, Guardamar del Segura y Torrevieja, tienen muy poco peso frente a la cofradía más importante de la provincia y de la Comunidad, la Cofradía de Santa Pola.

La Cofradía de pescadores de Santa Pola tiene el 33\% de la flota de la provincia, y el $12,5 \%$ de la Comunidad, seguida de la Cofradía de Gandía con el 10\% y el 9,4\% de la Cofradía de Castellón. A pesar de seguir siendo la Cofradía más importante ha sufrido una pérdida importante de embarcaciones del $27 \%$ en los últimos 10 años, si lo comparamos con hace 30 años el descenso llega al 63,9\%. El aumento en el número de embarcaciones se debió a las campañas de pesca que llevaba a cabo en el Atlántico. En cuanto al valor en lonja de pescado desembarcado en 2011 ascendió a los 16.388.877 €, lo que representa el 16,5\% del los ingresos generados en la Comunidad y el 45,6\% del volumen en la provincia. Además con respecto al año anterior se ha incrementado el valor de las capturas vendidas en la lonja de Santa Pola en un 9,5\%. 
Figura 14. Evolución de la flota según la Cofradía
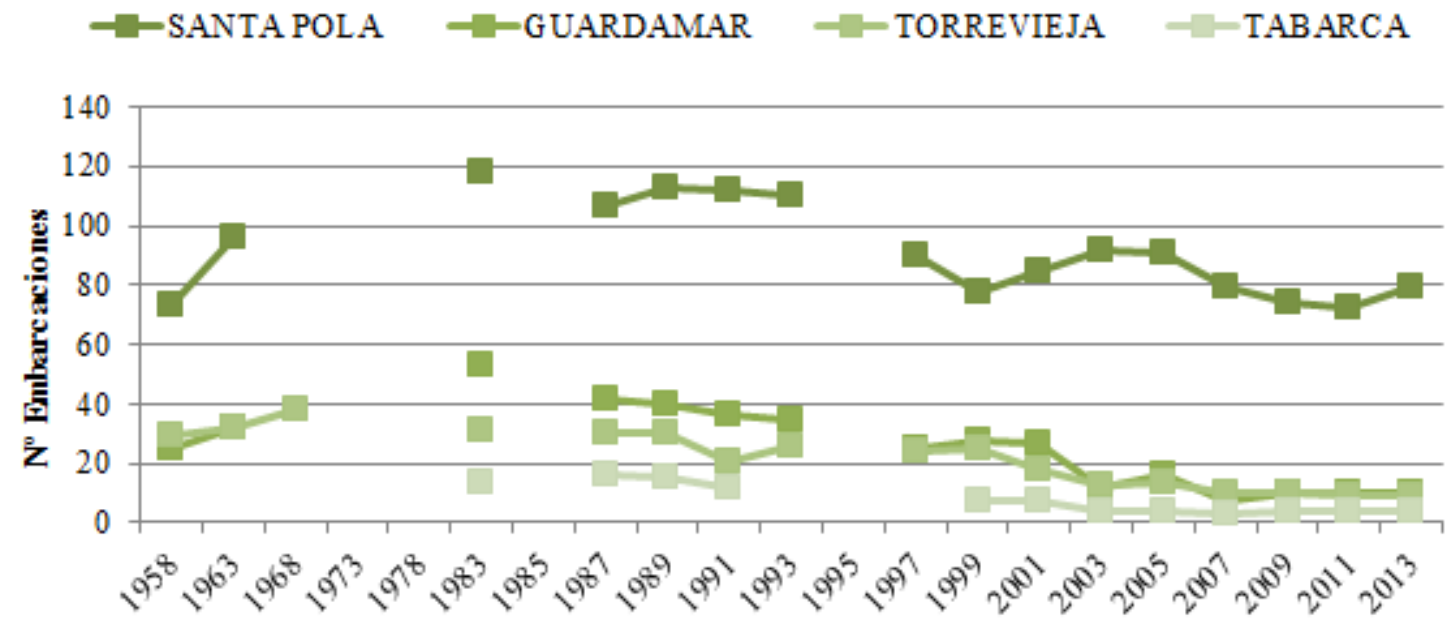

Fuente: Federación Provincial de Cofradías de Pescadores. Elaboración propia.

Figura 15. Proporción de barcos por cofradías

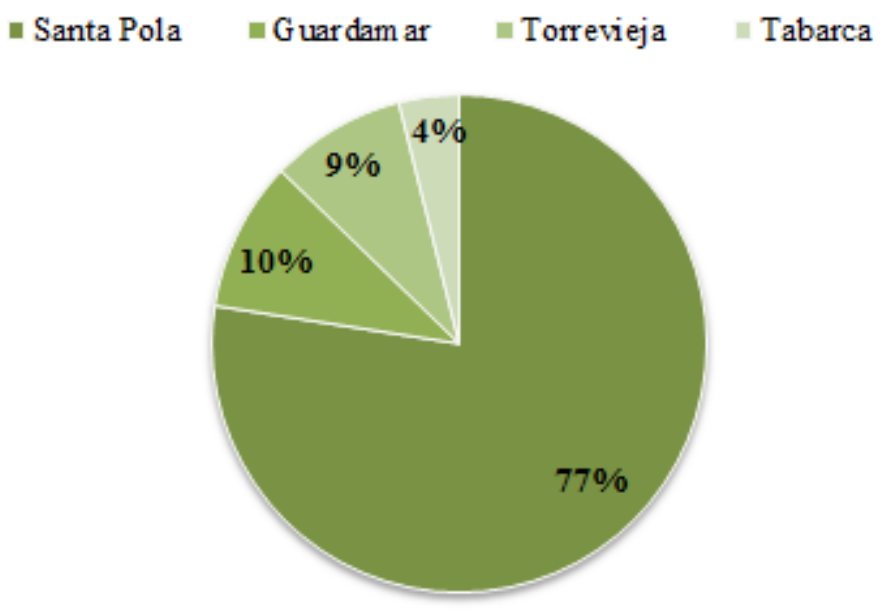

Fuente: Federación Provincial de Cofradías de Pescadores. Elaboración propia.

Ante estas cifras la importancia del resto de Cofradías de su entorno se ve claramente mermada. La Cofradía de Tabarca que no posee lonja desembarca sus capturas en la lonja de Santa Pola, y no lo hace en otra del entorno porqué la dinámica de ésta no es comparable a ninguna otra próxima. De hecho la Cofradía de Guardamar sólo pesca cerca del litoral con otras artes, mientras que Torrevieja es de las pocas Cofradías que aún practican la pesca con cerco. 


\section{PROBLEMAS EN EL SECTOR PESQUERO}

\section{La Política Pesquera Común (PPC)}

La historia del sector pesquero mediterráneo tiene su punto de inflexión en 1986, año en el cual España entra a formar parte de la entonces Comunidad Económica Europea. Con la entrada de España se integra uno de los países pesqueros más importante del mundo. Este hecho supone no sólo la adaptación de las políticas pesqueras españolas a la normativa comunitaria sino que también se produce un proceso de alimentación a la inversa debido a la magnitud del sector a nivel internacional.

La flota pesquera española ha buscado constantemente nuevos caladeros que aumenten la rentabilidad del sector para ello no dudaba en desplazarse hasta aguas del Atlántico sur o Terranova. Esta situación hizo que aumentaran las dimensiones de la flota en el marco de la libertad de los mares. La primera adaptación a la que se vio forzada fue tras la III Conferencia de la Naciones Unidas sobre el Derecho de los Mares y la instauración de las Zonas Económicas Exclusivas (ZEE). En consecuencia a partir de 1983 la Política pesquera española tiene como objetivo la adecuación de la flota al nuevo panorama existente.

La Política Pesquera Común (PPC) en ese momento se separa de la Política Agraria Común (PAC) y comienza un nuevo camino basado en tres ejes fundamentales: Recursos, Estructuras y Modernización. La Política de Recursos buscaba la conservación y gestión de recursos en aguas atlánticas. La Política de Estructuras iba encaminada a la financiación de pequeña cuantía, desarrollo de la acuicultura y financiar el abandono de la actividad. La Política de Mercados basada en la necesidad de abastecimiento de productos pesqueros, establecía precios de referencia o exención de tasas aduaneras. La Política Común Pesquera en 1986 estaba pensada y inclinada hacia las producciones del norte de Europa.

La adhesión de España recogía una serie de condiciones respecto al sector pesquero, que se establecían en el Tratado de Adhesión, entre ellas, la responsabilidad de la Comunidad por preservar las actividades de pesca de la flota española. Sin embargo España perdió las competencias en negociación de acuerdos pesqueros con terceros países que pasaron a ser gestionados por la CEE y se encontró en con una PPC en la que no había participado en su elaboración.

La postura de España ante las Políticas de Gestión y Conservación de Recursos tuvo un posición más laxa, dirigida hacia una diferenciación por regiones del sistema de totales admisibles de captura (TAC) y cuotas que permitan el aprovechamiento más racional de los recursos. La imposición de un TAC por especies crea situaciones de descarte de aquellos ejemplares que hacen superar la cuota establecida, lo que supone un desperdicio de recursos.

La Política Estructural buscaba un equilibrio entre los recursos disponibles y la capacidad de la flota. Con la renovación de los Reglamentos estructurales en 1986, España, consigue aportar una serie de novedades que afectan a las ayudas para modernización de barcos de mayores de $33 \mathrm{~m}$, ayudas a los jóvenes pecadores, períodos de inactividad de entre 60 y 150 días subvencionados. Durante las reformas de la PPC que se llevan a cabo durante los años 90 se consigue financiación para embarcaciones 
de pesca costera que busquen modernizar o sustituir sus barcos, y que las reducciones de la flota sean en función de la capacidad de explotación de los caladeros.

Con las reformas de la PPC de 2002 se eliminan las subvenciones al aumento de capacidad de embarcaciones y a la construcción de nuevos buques. Se pretende con estas medidas reducir una flota sobredimensionada para la explotación sostenible de los caladeros, que en la actualidad se encuentran sobreexplotados. Desde la UE consideran que la capacidad de carga actual es el doble de la necesaria. De este modo se introduce la vertiente medioambiental en un sector que depende totalmente del medio natural, así bajo, el calificativo de "sostenible", "sostenibilidad", etc... se ponen en marcha medidas que acarrean la desaparición de embarcaciones dedicadas a la pesca. Los TAC y cuotas desde 2002 serán competencia de las políticas pesqueras nacionales.

Con una perspectiva para 2020 la pesca en Europa pone en marcha en 2009 el Libro Verde con las nuevas líneas de actuación entre las que destaca la integración de las PPC en el Plan Marítimo Integral, así como continuar la protección medioambiental de los fondos marinos y conseguir una flota con capacidad de captura equivalente a la población de peces en los caladeros y su explotación sostenible.

Aunque la PPC es aplicable a todo el ámbito pesquero comunitario, el Mediterráneo en el momento en que España ingresa en la CEE se encuentra en un estatus diferente. En primer lugar las políticas que se ponen en marcha en la primera PPC de 1983 se basan en un perfil del sector orientado al modelo de actividad pesquera que llevan a cabo los países del norte de Europa. Pero el Mediterráneo presenta un particularidad respecto a la vertiente atlántica y es que no es de aplicación una ZEE ya que son numerosos los países ribereños, de modo que la pesca en determinadas aguas depende de permisos y acuerdos entre los diferentes países.

El propósito de España desde el momento de ingreso en la CEE es establecer un Política de Conservación específica del Mediterráneo, sin que fuera un copia literal e inaplicable de la empleada para el Atlántico. Uno de los mayores motivos que mueven esta iniciativa española es la captura incontrolada que están llevando a cabo en el Mediterráneo pesqueros de gran envergadura de origen italiano. Estos grandes buques durante los años 70 barrieron los fondos marinos con pesca de arrastre de grandes proporciones llevando al límite muchos de los caladeros donde faenaban los barcos españoles, concretamente los de la provincia de Alicante. Esta faena de pesca con redes de deriva no es selectiva y puso en peligro la biodiversidad mediterránea. Junto con estos grandes petroleros transformados en buques de actividad extractiva cada vez es mayor la presencia de grandes embarcaciones industriales.

A principios de la década de los años noventa se pone en marcha la Propuesta de Reglamento por la que se armonizan determinadas medidas técnicas vigentes en el Mediterráneo en las que las Cofradías del Mediterráneo y sobre todo la alicantina a través de la Federación Provincial tuvieron mucho que decir. En el interior del documento se recogen las medidas mínimas y máximas de los aparejos, en cuanto a enmalle y dimensiones. Además establece las distancias a las que se pueden llevar a cabo la pesca con determinadas artes. Por ejemplo, en su artículo 3 se establece que la prohibición de utilizar cualquier tipo de red de arrastre dentro del límite de las 3 millas náuticas o de la isóbata de $50 \mathrm{~m}$ cuando esa profundidad se alcance a menor distancia. 
Las Políticas europeas están cargadas de buenas intenciones que no han hecho más que hacer desaparecer el sector pesquero alicantino de altura, reduciéndolo exclusivamente en la actualidad a las artes de bajura. La búsqueda de la sostenibilidad del medio marino y los incentivos al desguace de la flota provocan que cada año se reduzca el número de buques en las Cofradías. Estas ayudas las percibe el armador de forma inmediata en cuanto desmantela su embarcación. Un motivo más por el cual cada año se desguazan más barcos por la inmediatez de la indemnización.

Además de la subvención ya referida al cese de la actividad, existen otras que ni mucho menos favorecen el desarrollo de la actividad pesquera. Por un lado existen ayudas para los pescadores cuando se llevan a cabo las paradas biológicas, sin embargo la dilatación en el tiempo para que el marinero perciba la prestación genera grandes repercusiones sociales. La tardanza en el pago se debe a que la UE paga las ayudas a través de la Generalitat Valenciana. Cambiar este sistema de cobro de las ayudas a pescadores por los paros biológicos, de manera que la UE las abone directamente, es uno de los objetivos por los que las diferentes Federaciones provinciales están luchando en el día de hoy.

Muchos pescadores prefieren engrosar las listas del paro que esperar la llegada de las ayudas europeas, con el consiguiente consumo de la prestación por desempleo. Esta situación provoca que llegado determinado punto se agote la ayuda del paro debido a que el pescador no vuelve a acumular los meses mínimos necesarios para poder acceder de nuevo a ella. Esta paradoja evidencia la mala gestión de las mismas.

Pero la subvención europea que genera más indignación entre el mundo marinero es la destinada a realizar campañas publicitarias para la captura y consumo de peces de talla ecológica. En este caso las campañas no son llevadas a cabo por las Cofradías, o no se destinan a la adquisición de aparejos con las dimensiones que no permitan la captura de ejemplares por debajo del tamaño mínimo. Estas campañas son llevadas a cabo por le Ministerio de Agricultura, Alimentación y Medio Ambiente, actualmente, por lo que los beneficios son para las compañías publicitarias contratadas por la Administración central.

La última novedad de acuerdo con la normativa europea es la instalación de Sistemas de Localización de Buques Pesqueros (SLB). La implantación de estas cajas azules no alcanza aún los dos años y su finalidad es que las autoridades competentes puedan localizar los buques pesqueros de eslora superior a $15 \mathrm{~m}$. El Centro de Seguimiento de Pesca (CSP) español es el encargado de recoger y almacenar la información que vía GPS envían las cajas azules para, en su caso, facilitar la posición de los buques españoles a los países en cuyas aguas están faenando o recibir la información del CSP extranjeros que se encuentran en aguas españolas de modo que se puedan establecer sanciones a aquellas embarcaciones que no cumplan la normativa.

\section{Comercialización de productos pesqueros}

Los problemas del sector pesquero de bajura por su falta de rentabilidad se deben principalmente a dos factores: el aumento de los gastos de explotación y la falta de captura de especies más rentables. 
En los últimos años se han ido incrementado los gastos asociados a la explotación pesquera. La subida del precio del combustible ha sido el causante de la caída en picado de la rentabilidad de la actividad. Frente a esta situación los precios del pescado en primera venta no han experimentado la subida necesaria para hacerles frente, sino que estos se venden más baratos en subasta.

Cuadro 3. Comparación de las especies con mayor valor en lonja con su PVP en el comercio detallista del Mercado de Abastos de Alicante. Abril 2013

\begin{tabular}{|c|c|c|c|c|c|}
\hline Especies & $\begin{array}{l}\text { Kg. } \\
\text { desembarcados }\end{array}$ & $\begin{array}{l}\text { Valor en lonja } \\
\text { anual (€) }\end{array}$ & $\begin{array}{l}\text { Valor } \\
\text { medio } \\
(€ / \mathrm{kg})\end{array}$ & $\begin{array}{l}\text { P.V.P. Mercado } \\
\text { Abastos (€) }\end{array}$ & $\begin{array}{l}\text { Incremento } \\
\text { de precios } \\
(\%)\end{array}$ \\
\hline Boquerón & 323.483 & 447.179 & 1,38 & 7,35 & 81 \\
\hline Corvina & 1.457 & 6.675 & 4,58 & 16,00 & 71 \\
\hline Lubina & 663 & 5.905 & 8,91 & 30,00 & 70 \\
\hline Merluza & 35.043 & 113.055 & 3,23 & 10,00 & 68 \\
\hline Mejillón & 450 & 839 & 1,86 & 5,20 & 64 \\
\hline Sardina & 103.805 & 182.038 & 1,75 & 4,80 & 63 \\
\hline Congrio & 4.667 & 6.299 & 1,35 & 3,50 & 61 \\
\hline Rape & 29.318 & 136.692 & 4,66 & 11,64 & 60 \\
\hline Pulpo & 111.071 & 237.321 & 2,14 & 4,35 & 51 \\
\hline Gamba & 24.274 & 548.317 & 22,59 & 35,80 & 37 \\
\hline
\end{tabular}

Fuente: Federación Provincial de Cofradías de Alicante. Elaboración propia.

Esta situación a la baja del precio del producto pesquero tiene relación con el control que ejercen los grupos del sector comercial. Es evidente el papel fundamental del comercio para llevar el pescado al consumidor sin embargo la falta de transparencia en determinados procesos de distribución tan sólo buscan un mayor beneficio en perjuicio de la rentabilidad del pescador.

La escasa transparencia se observa cuando encontramos comercios que no cumplen con las normas establecidas de etiquetado de los productos pesqueros, práctica habitual en muchos establecimientos de venta al público. Mejorar este aspecto repercutiría en beneficio de ambas partes, comerciantes y pescadores, ya que permitiría ofrecer productos de calidades, procedencias y precios distintos.

Esta situación de desventaja del pescador provoca que las Cofradías busquen alternativas que aumenten los ingresos del producto. En ocasiones ha habido iniciativas de venta directa con resultados no deseados, pues se les acusa de invadir un nicho de mercado que no les compete.

Otro factor que resta rentabilidad es la llegada de pescado de importación que rompe los precios de mercado y no garantiza la calidad ni la autenticidad de origen que declara el producto. En este sentido se requiere desde el sector más control de los desembarcos foráneos por parte de la Inspección Pesquera y de las Lonjas. 
El consumidor final juega un papel importante con sus hábitos de consumo. Por un lado la gente joven es menos consumidora de pescado fresco y más de productos semielaborados o elaborados que reducen el tiempo de preparación en la cocina. La incorporación de la mujer al mundo laboral tiene mucho que ver con este cambio. Por otro lado, la demanda estacional de determinadas especies como el marisco, es el ejemplo paradigmático de como en época de Navidad sufre una subida elevada de su precio. Una estabilidad durante todo el año de los precios es preferible a estas situaciones tan puntuales en el calendario.

Por último, otra cuestión a tener en cuenta es la gran variedad de oferta, no en cuanto a especies de pescado, sino en cuanto a puntos de primera venta, es decir, de lonjas. Se puede afirmar que cada localidad pesquera tiene su lonja y sus subastas. Esta fragmentación en el territorio dificulta la creación de acuerdos que estabilicen un mercado que necesita medidas para aumentar su rentabilidad.

\section{Falta de mano de obra}

Una de las principales debilidades del sector pesquero alicantino es la ausencia de mano de obra cualificada. Esto se debe principalmente a los bajos salarios que se perciben, por lo que la gente más preparada y joven busca empleo en sectores más rentables. Aunque en los últimos años esta tendencia de migración a sectores económicamente más atrayentes se produce también con la mano de obra no cualificada. Al final los puestos vacantes en las tripulaciones cada vez mas mermadas se ha suplido con la inmigración.

Los salarios en el mundo de los pescadores se realizan a la parte, es decir, es un sistema por el cual los ingresos obtenidos se reparten entre el armador, propietario de la embarcación, y los tripulantes. El reparto se realiza normalmente a la semana, pero existen tripulaciones que lo realizan a la quincena $\mathrm{y}$, son menos, las que lo hacen mensualmente. El fraccionamiento de los ingresos se realiza de la siguiente manera; en primer lugar se descuentan los gastos corrientes de gasóleo, manutención, seguros sociales, etc., del resto, la mitad es para el armador y la otra mitad se divide a la parte entre la tripulación. Este último reparto a la parte no tiene por que ser a partes iguales, sino que se realiza según los acuerdos que existan entre los pescadores, así el patrón se puede llevar dos partes, y el resto de marineros una, por ejemplo.

En la actualidad se exige cierta especialización a la hora de trabajar en la mar. Sin embargo son pocos los jóvenes que se forman en los centros especializados para impartir los programas dirigidos al sector de la pesca. Alicante cuenta con el Instituto Politécnico Marítimo Pesquero del Mediterráneo, único centro de estas características en la Comunidad. Una cuota de alumnos en descenso pone al Instituto en una situación compleja ya que existe un dilema sobre que Ministerio debe asumir las competencias de la institución educativa. Actualmente está dentro de los presupuestos del Ministerio de Agricultura, Alimentación y Medio Ambiente quien insta al Ministerio de Educación a que asuma las competencias sobre los centros de estas características.

Otro factor relevante es el envejecimiento de la mano de obra, cada vez más los armadores y patrones son de edades más avanzadas, que no encuentran en sus familias el reemplazo generacional para continuar con la actividad, lo que conlleva al abandono de la pesca o en el mejor de los casos, alquilan las embarcaciones a terceros para su 
explotación. Hay que tener en cuenta que la edad de jubilación de los marineros es de 55 a 57 años.

Figura 16. Evolución del número de tripulantes totales por cofradías

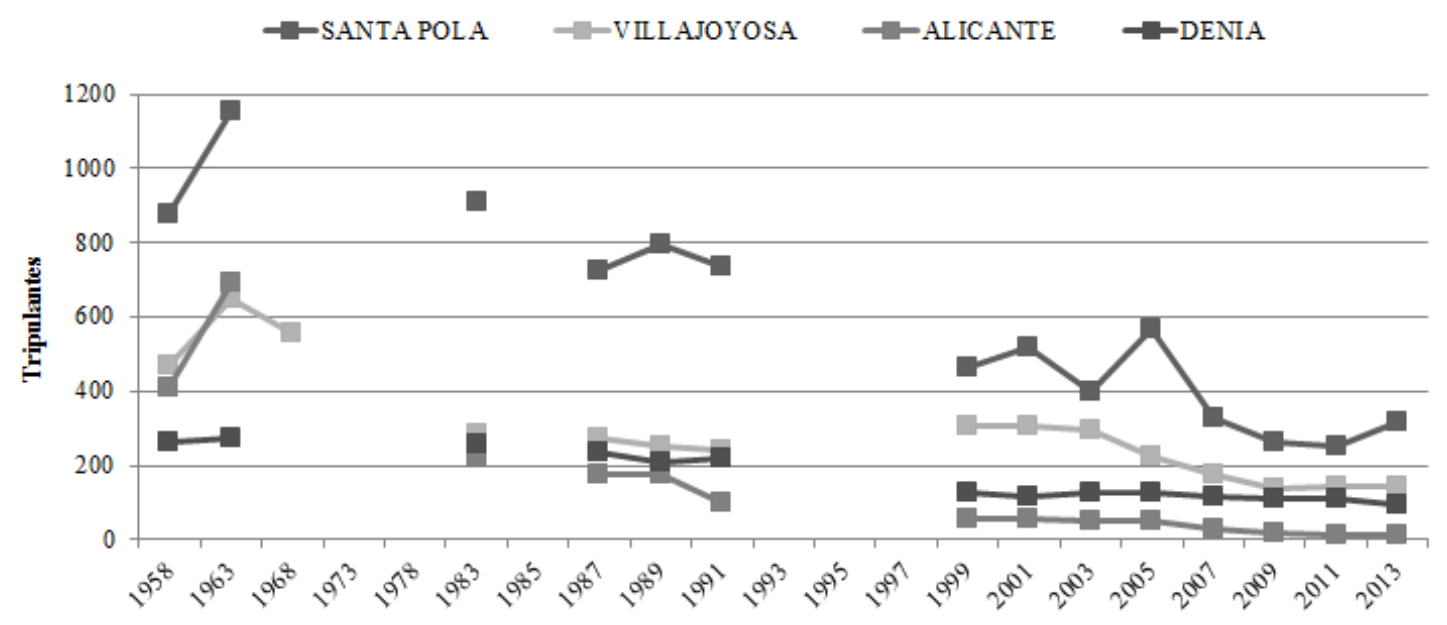

Fuente: Federación Provincial de Cofradías de Alicante. Elaboración propia.

En el contexto actual de crisis económica en el que nos encontramos se está produciendo una vuelta a los trabajos tradicionales, como la pesca, de ahí que podamos ver que en algunos casos la pérdida de tripulantes no sigue la tendencia tan acusada de los últimos años o que en algún caso haya un aumento de mano de obra en Cofradías como la de Altea, Villajoyosa y Santa Pola (Figura 16).

\section{El caso de la Lonja de Alicante}

Entre los años 70 y 80 de siglo XX la lonja de Alicante fue de las más potentes del Mediterráneo occidental. Durante aquellos años la lonja de Alicante era la que más pescado fresco vendía de toda España, siendo la más importante en venta de pescado de corte, es decir de emperador y atún. Las artes empleadas para la captura de estas especies era la pesca con palangre en superficie.

La entrada en el puerto de estas especies se producía los lunes al atardecer o los martes de buena mañana para entrar directos a la subasta de este tipo de productos, que tenía lugar los martes a partir de las 4.00 horas de la mañana. El número de embarcaciones que podían darse cita un martes cualquiera rondaba las 15 ó 20, las cuales desembarcaban un volumen de captura de emperador que podía alcanzar cifras de 50 ó 60 piezas por buque. El tamaño medio de estos ejemplares rondaba los 25 kilogramos los más pequeños hasta los 40 kilogramos de peso los de mayor tamaño. El desembarque en puerto se llevaba a cabo una vez por semana.

La llegada de atún al puerto alicantino tenía menos frecuencia y el número de piezas era considerablemente menor, entre los 6 ó 7 ejemplares por embarcación, sin embargo el peso por unidad podía alcanzar los 150 kilogramos. 
La ausencia en aquellas décadas de medidas que regulasen la captura, tanto de atún como de emperador, pusieron en serio peligro la pesca de ambas especies que aún a día de hoy se resienten por la sobreexplotación a la que se vieron sometidas. Tanto las normativas estatales como las europeas han puesto tope a su captura estableciendo medidas mínimas de tamaño y de kilogramos de peso, superado alguno de estos umbrales está prohibida su comercialización. Estas medidas proteccionistas han permitido los procesos de regeneración de los caladeros de manera gradual. A pesar de todo en la actualidad es imposible que se den situaciones como las vividas hace más de veinticinco años en la lonja de Alicante.

Junto con las embarcaciones de arrastre, llegaban también los barcos de cerco con luz. La riqueza de los caladeros de sardina y boquerón en la bahía de Alicante daba lugar a concentraciones de aproximadamente 50 buques de pesca. Al llegar el día arribaban al puerto de Alicante a vender su faena. Cada barco en aquel momento podía acarrear un volumen de pesca de 400 cajas por día. Teniendo en cuenta que las cajas de pescado actuales son de 10 kilogramos y antes su capacidad estaba entre los 15 y 20 kilogramos, podían llegar a la lonja de Alicante volúmenes de en torno a los 7.000 kilogramos por barco. Al igual que sucedió con la pesca de arrastre, en el cerco también se ha impuesto un sistema de totales admisibles de captura y cuotas, para permitir un desarrollo sostenible de los caladeros.

Además de los barcos de las Cofradías más próximas de la provincia de Alicante y de la Comunidad Valenciana, llegaban al puerto de Alicante embarcaciones de Baleares, Almería, Algeciras, etc. a vender sus productos en la lonja alicantina. Incluso llegaban camiones refrigerados con mercancía para la subasta en la lonja de Alicante.

La lonja de Alicante daba trabajo a más de treinta personas que se distribuían entre personal administrativo, subastadores, gente de la colla que preparaba el pescado para la subasta. La subasta era a voz, según la forma tradicional. En los momentos de máxima afluencia de embarcaciones llegaban a estar seis personas subastando a la vez, aunque dos de ellos se dedicaban en exclusiva a la subasta de pescado de corte. El emperador y el atún se vendían limpios, es decir abiertos, sin tripas y sin cabeza. Esta labor la realizaba la colla de la Cofradía de Alicante.

Uno de los puntos fuertes de la lonja era su ubicación estratégica hacia el sur de la ciudad en una zona del puerto alejada del tráfico de recreo y de fácil acceso por carretera.

Esta situación de bonanza se va diluyendo a medida que nos adentramos en los años 90 cuando las cosas iban bien y el dinero fluía con facilidad. Entre los factores que propiciaron su declive se destaca la aparición de un negocio ilegal que creó un mercado a espaldas de las normas establecidas en el sector y de la propia lonja.

Los mayoristas de distribución compraban en la lonja grandes cantidades de boquerón, sardinas y emperador y a su vez tenían permitida la venta de pescado fresco traído de otros puertos. Éstos vendían después de la venta primera, es decir, la de las embarcaciones que venían a descargar sus capturas en el puerto de Alicante. Esta situación de competencia de venta entre pescadores y distribuidores se fue agudizando hasta tal punto que había distribuidoras que pactaban con determinadas embarcaciones la compra de su cargamento a mejor precio del que podían tener de la venta en lonja. 
Poco a poco fue aumentando la venta directa de pescado frente a la venta que pasaba por la lonja.

A esta situación de competencia desleal se une el despilfarro de dinero en grandes obras que resultaron ser un fracaso, entre las que destacan la fábrica de hielo y la nueva lonja de Alicante. Estas actuaciones son el resultado de los importantes beneficios obtenidos durante la época de máximo dinamismo, la primera de ellas que decide llevar a cabo la Cofradía de Alicante es la construcción de una nueva fábrica de hielo.

La Nueva Lonja de Alicante fue realmente la gran obra que quiso ejecutar la Cofradía, con el beneplácito de la Autoridad Portuaria. Los costes de la construcción del nuevo edificio serían sufragados por la subvención europea para la modernización de estructuras. Se levantó la lonja más grande de España con los medios más avanzados. La planta superior estaba prevista para la instalación de un par de restaurantes. La nave principal de la lonja se proyectó con la intención de reservar un espacio a los mayoristas. Se hicieron una serie de puestos con la intención de alquilarlos a los mayoristas de pescado para que pudieran vender sus mercancías, propuesta que contaba con la aprobación de este colectivo. Sin embargo en última instancia se les solicitó que en lugar de pagar un canon por el uso de los puntos de venta, deberían pagar la parte proporcional de la construcción de la lonja. El resultado fue rotundo, una negativa.

La respuesta que llevó a cabo la Asociación de Mayoristas de Alicante, fue la adquisición de unos terrenos colindantes a los de la Nueva Lonja para levantarse una nave de venta y distribución para su sector de actividad.

La falta de recursos para sufragar los gastos de la construcción de la Nueva Lonja de Alicante, el retraso en el cobro de la subvención y la salida de los mayoristas del proyecto, sumieron en una profunda crisis a la Cofradía de Alicante que no pudo asumir los pagos. Estos acontecimientos tuvieron lugar hace ocho años, y nunca se ha puesto en funcionamiento la lonja, actualmente se encuentra cerrada y embargada por las entidades financieras.

La Cofradía de Alicante desde que comenzó este periodo de decadencia, ha ido experimentado un retroceso tan acusado que en 2013 sólo cuenta con 4 embarcaciones, todas ellas de artes menores de captura en la bahía. La situación a la que se enfrenta en un futuro es muy delicada. Ha pasado de ser la Cofradía y lonja de referencia nacional a encontrarse a punto de la desaparición.

Recientemente ha habido una serie de intentos por abrir la Nueva Lonja, todos ellos por grupos y asociaciones de mayoristas pero para poner en marcha la instalación, es competencia del Consell dar el visto bueno. La decisión que se tome tendrá importantes consecuencias para el sector pesquero porque supone la entrada de mayoristas y detallistas en la gestión de las lonjas, la cual actualmente está limitada a la cofradías. La gestión por parte del sector mayorista supondría la liberalización de ventas en la lonja pudiendo llegar embarcaciones de cualquier procedencia sin pasar por los controles de calidad que se asocian a las Cofradías.

Además supondría desplazar de su actividad tradicional a las Cofradías que verían disminuir su peso en un sector que hoy, busca la máxima rentabilidad a través de la 
acuicultura y las capturas procedentes de las grandes navieras de distribución internacionales, alegando la baja o nula rentabilidad de la pesca tradicional.

\section{CONLUSIONES}

Del estudio detallado de todos los indicadores que nos ofrece la Federación Provincial de Cofradías de Alicante y que se han ido comentando a lo largo del trabajo se desprende un hecho irrefutable, el sector pesquero alicantino se encuentra en un proceso de retroceso como consecuencia de la falta de rentabilidad.

A partir de este punto son muchos los factores y matices que de forma tangencial contribuyen en mayor o menor medida al desmantelamiento de la flota pesquera de la provincia.

Es evidente el cambio en la dinámica del sector desde el momento en que España entra a formar en 1986 parte de la CEE. En la etapa preeurpea la flota española era una de las principales potencias a nivel mundial y contaba con numerosas embarcaciones que faenaban en altura durante largos periodos de tiempo. Desde el momento que España firma el Tratado de Adhesión se aplica a nuestras embarcaciones políticas pesqueras basadas en la pesca que se practica en el norte de Europa. Poco a poco, sobre todo en el Mediterráneo, donde Alicante era una gran potencia, se inicia un proceso de reconversión del sector pesquero que acaba con todas las embarcaciones de altura de la provincia. La entrada en vigor de la PPC supone la transformación del sector pesquero alicantino a un modelo de pesca tradicional y de bajura.

La PPC ha diezmado las embarcaciones de las Cofradías alicantinas amparada en la sostenibilidad de los caladeros ante una flota sobredimensionada. Es cierto que había que regular la cuota de capturas para no acabar con los recursos marítimos, pero ¿a qué precio? A costa de la destrucción de miles de puestos de trabajo, ya que al armador le es más rentable mandar el barco al desguace que seguir saliendo a faenar. Al igual que sucede con la PAC, las líneas de ayuda no han ido encaminadas a transformar la actividad pesquera en un sector eficiente y rentable que pueda competir con potencias como China o Japón, quien en la actualidad es la potencia hegemónica en la explotación pesquera.

De modo que llegamos al punto actual con un sector con un alto índice de parados, sin incorporación al mercado de trabajo de gente joven cualificada, con una población activa envejecida que piensa más en su jubilación que en rentabilizar su explotación y la aparición de nuevos agentes externos en el panorama pesquero.

Uno de los agentes a los que se hace referencia es Cairn Energy, la empresa concesionaria de las prospecciones petrolíferas en el Golfo de Valencia. Las licencias para dichas actuaciones fueron avaladas por el Gobierno en 2010, para llevar a cabo catas frente a las costas de la Albufera, Benifaió, Gandia y el Golfo de Valencia.

Esta situación pone en serio peligro los caladeros existentes en la zona. Las Federaciones provinciales de Cofradías de Alicante, Valencia y Castellón se oponen frontalmente ya que las ondas acústicas que se emiten perjudican seriamente a la fauna marina, pues afectan a la vejiga natatoria de los peces y estos mueren. 
Según diversos artículos de prensa, el Tribunal Supremo ha desestimado el recurso puesto por la Generalitat para evitar que se ejecuten. Habría que investigar con mayor profundidad para conocer realmente los intereses ocultos que están detrás de la aprobación de estas catas, que ponen en peligro tanto el sector pesquero como el turismo. Seguramente exista algún tipo de lobby de presión puesto que según las noticias publicadas en prensa carecen de los pertinentes Informes de Impacto Ambiental, el Informe requerido por la Ley de Pesca Marítima o la autorización previa de la Ley de Costas, además enumeraran una serie de incumplimientos de las directrices comunitarias.

Las Asociaciones de mayoristas o de Detallistas son la otra amenaza externa a la que se enfrenta el sector. Éstas pretenden arrebatar a las Cofradías sus competencias sobre la gestión de las Lonjas. Si se diera el caso de que al final estas asociaciones consiguen sus objetivos habrán herido de muerte tanto a las Cofradías como a las embarcaciones familiares y tradicionales que en la actualidad faenan en nuestras aguas. El porqué es sencillo, su objetivo es la obtención de los máximos beneficios con lo que recurrirán a embarcaciones de países donde la mano de obra es más económica y abrirán las lonjas a los desembarcos de productos que no han sido certificados como de calidad, acabando con la garantía de frescura que ahora ofrecen las Cofradías.

El producto que ofrecen las Cofradías y que llegan al consumidor final cuenta con una calidad inigualable en cuanto a la frescura y excelencia nutricional, valores que le han servido a nuestros pescados para posicionarse en el mercado nacional que le exige una gran demanda.

Esta demanda avalada por la calidad del producto es en la actualidad una de las vías de escape del sector, pues con las embarcaciones que cuenta la provincia no se abastece el mercado de la demanda. De modo que permitiría la aparición de nuevos armadores que busquen en la pesca una salida a la situación actual de paro y crisis, volviendo de esta forma a la tradición familiar pesquera.

La pérdida de un sector tan arraigado en nuestra tierra que es el núcleo originario de muchas de nuestras localidades, supone perder un legado cultural de importantísimo valor. En la era de las tecnologías y los avances aún se siguen realizando a mano las redes de pesca. Las Cofradías representan un importante papel asistencial y de formación buscando el bien común de la comunidad, premisas ya formuladas en la época medieval. La gastronomía alicantina incorpora incontables productos del mar que la han convertido en la dieta mediterránea por excelencia.

La pesca no es solo una actividad económica lleva detrás un modo de vida que pasa desapercibido en la sociedad de consumo actual, por ese motivo las Administraciones locales, autonómicas y central deben poner sus esfuerzos en rescatar la pesca tradicional de bajura, ya que si no se pone remedio pronto, en un corto-medio plazo, acabará desapareciendo por completo.

\section{BIBLIOGRAFÍA}

Asociación Española de Ciudades de la Pesca. El sector pesquero en la provincia de Alicante. Alicante: Diputación Provincial, 2002, 205 p. 
CAMARASA GARCÍA, Ma . Estela. La pesca en la provincia de Alicante. Valencia: Universidad de Valencia, 1975, 93 p.

Comisión de las Comunidades Europeas. Libro Verde. Reforma de la Política Pesquera. Bruselas, 2009.

Comisión de las Comunidades Europeas. Reglamento (CEE) del Consejo por el que se armonizan algunas medidas técnicas vigentes en el Mediterráneo. Bruselas, 1993.

Comité Económico Social de la Comunidad Valenciana. Memoria sobre la situación socioeconómica y laboral de la Comunidad Valenciana. Valencia: Generalitat Valenciana, 2000.

Comité Económico Social de la Comunidad Valenciana. Memoria sobre la situación socioeconómica y laboral de la Comunidad Valenciana. Valencia: Generalitat Valenciana, 2009.

Foro Científico sobre la Pesca Española en el Mediterráneo. VII Reunión del Foro Científico sobre la Pesca Española en el Mediterráneo. Alicante: Editorial, Club Universitario, 2002, $137 \mathrm{p}$.

LLORET SORIANO, Gaspar. A la búsqueda de un sector pesquero sostenible. Geographos [en línea], 2011, vol. 2, nº 12 [16 de junio de 2011], 34 p. Disponible en: $<$ http://web.ua.es/es/revista-geographos-giecryal/documentos/articulos/a-la-busquedade-un-sector-pesquero-sostenible.pdf?noCache1309623458477>.

LORIA RUA, José. La política pesquera española. Tribuna, 1993, nº 6, p. 54-65.

MÁS y GIL, Luis. La pesca en Alicante (ensayo para su historia). Alicante: Confederación Española de Cajas de Ahorro, 1979, 173 p.

\section{RECURSOS ELECTRÓNICOS}

Comisión Europea. La Política Pesquera Común. Guía del usuario [en línea] Luxemburgo: Oficina de Publicaciones de las Comunidades Europeas, 2009, 36 pp. [22 de abril de 2013]. Disponible en: $<$ http://ec.europa.eu/fisheries/documentation/publications/pcp2008_es.pdf $>$.

Comité Económico Social de la Comunidad Valenciana. Memoria sobre la situación socioeconómica y laboral de la Comunidad Valenciana [en línea]. Valencia: Generalitat Valenciana, 2011. Disponible en: $<$ http://www.ces.gva.es/cs_htm_trabajos/trabajos_mem_socio_2011.htm>.

Departamento de pesca y acuicultura. Food and Agriculture Organization of United Nations. [7 de junio de 2013]. Disponible en: < http://www.fao.org/fishery/es $>$. 
Pesca. Ministerio de Medio de Agricultura, Alimentación y Medio Ambiente [en línea] 2013 [22 de abril de 2013]. Disponible en: < http://www.magrama.gob.es/es/pesca/temas/default.aspx $>$.

Diario Información. [7 de junio de 2013]. Disponible en: $<$ http://www.diarioinformacion.com/alicante/2012/02/04/solicitan-reapertura-lonjapescado-puerto-alicante/1219571.html>.

Europapress. [7 de junio de 2013]. Disponible en: $<$ http://www.europapress.es/sociedad/noticia-supremo-avala-prospeccionespetroliferas-valencia-20130422134102.html >.

Página noticias. $[7$ de junio de 2013]. Disponible en: $<$ http://www.paginanoticias.es/n/Espana/74vox3z64/Consell-Puerto-pactan-reabrir-laLonja-de.htm>.

(C) Copyright Francisco Calatayud Díaz, 2014.

(C) Copyright GeoGraphos, 2014.

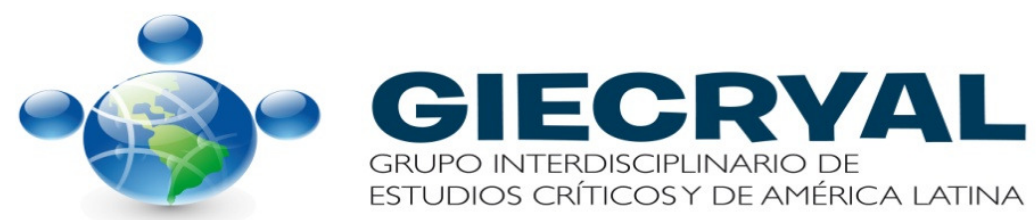

